\title{
Mudança de Cultura e Gestão Estratégica de Pessoas em uma empresa de criação e produção de conteúdo audiovisual
}

\author{
Culture Change and strategic people management in an audiovisual
} content creation and production company

Thiago Lise Schäfer ${ }^{1}$

Lisiane Lise Schäfer ${ }^{2}$

\begin{abstract}
Resumo:
No contexto da evolução tecnológica na criação e produção de conteúdo audiovisual o trabalho analisou o desdobramento de uma nova estratégia organizacional na cultura de uma organização. Uma pesquisa exploratória foi realizada por meio de revisão bibliográfica e posterior estudo de campo qualitativo em entrevista com colaboradores. 0 trabalho possibilitou conclusões a respeito da importância de times de alta performance na garantia da sustentabilidade de uma empresa como mediatech.
\end{abstract}

Palavras Chave: Criação e Produção Audiovisual; Gestão da Mudança; Cultura organizacional; Gestão Estratégica de Pessoas.

\begin{abstract}
:
In the context of technological evolution in the creation and production of audiovisual content, the work analyzed the unfolding of a new organizational strategy in the culture of an organization. An exploratory research was carried out through a bibliographic review and subsequent qualitative field study in an interview with employees. The work enabled conclusions about the importance of high performance teams in guaranteeing the sustainability of a company like mediatech.
\end{abstract}

Keywords: Audiovisual Creation and Production; Change management; Organizational culture; Strategic People Management.

\section{INTRODUÇÃO}

O mundo vive uma era de transformações rápidas e crescentes. A incerteza quanto ao futuro e a mudança contínua são características percebidas em todos mercados. Isso fica ainda mais evidente na indústria de Mídia e Entretenimento, a qual desde sua origem apresenta muita criatividade, inovação e empreendedorismo na forma como se relaciona com seus clientes, parceiros e telespectadores. Neste sentido, o presente trabalho busca identificar a evolução das estratégias de Gestão de Pessoas na Mudança Cultural em uma empresa de criação e produção de conteúdo audiovisual.

A empresa deste estudo de caso iniciou suas atividades como uma empresa de criação, produção e distribuição de conteúdo audiovisual focada na televisão aberta brasileira. Desde a sua origem familiar, há aproximadamente 70 anos, apresentou rápido

\footnotetext{
${ }^{1}$ MBA em Gestão Estratégica de Pessoas - UFRJ - Rio de Janeiro/Brasil. E-mail: thiagolise@me.com

${ }^{2}$ Mestre em Gestão da Competitividade e Sustentabilidade - FGV - Rio de Janeiro/Brasil. E-mail: lisianelise@yahoo.com
} 
crescimento e expansão em todo território. Entretanto é no contexto dos anos 2000 que o esse mercado começou a modificar substancialmente.

Tendo em vista as mudanças no cenário brasileiro e mundial no que diz respeito à internet, tecnologia e entretenimento a empresa percebeu a necessidade de aprimorar sua estratégia organizacional. Não obstante permanecer renomada pelos seus conteúdos para televisão aberta como também aumentar a sua produção e possibilitar novas experiências aos seus consumidores através de outras plataformas. Sendo a nova estratégia fundamental para que de uma maneira flexível e adaptável a empresa se posicione frente ao contexto do mercado e agregue valor aos seus clientes, os valores são a missão, visão e princípios comuns no comportamento dos colaboradores que fazem parte do grupo.

Em um processo da mudança organizacional o papel da liderança é fundamental. Através de suas competências de gestão estratégica, pessoas e resultados é esperado que esses profissionais saibam analisar o contexto da organização e propor soluções para os problemas do presente tendo como norte o alcance da estratégia desejada. Os líderes têm atuação crucial ao assegurar que todas decisões disruptivas tomadas por si e executadas pelas equipes ocorram alinhadas à cultura esperada para o negócio. Entender qual é a visão das lideranças acerca da evolução das estratégias de recursos humanos na organização e suas percepções sobre as características da cultura organizacional consideradas gargalos ou oportunidades para o sucesso futuro da organização são pontos igualmente importantes a fim de entender a eficácia das ações.

Este trabalho é fruto de, inicialmente, uma pesquisa exploratória realizada por meio de revisão bibliográfica acerca do fenômeno da mudança no grande nicho de mercado da geração, consumo e compartilhamento de conteúdo audiovisual, correlacionando-o com conceitos modernos em Gestão de Pessoas e de um estudo de campo baseado nas percepções dos colaboradores. A abordagem é qualitativa visto que foram realizadas entrevistas com lideranças de uma empresa e de uma área específica desta organização.

A escolha é considerada a mais adequada pois os aspectos analisados são de natureza subjetiva e pragmática. Os resultados da pesquisa exploratória foram analisados junto ao entendimento de características dos profissionais entrevistados que trabalham na área tais como idade, tempo no cargo e tempo de casa. Sendo assim, a pesquisa também se enquadra na categoria descritiva. A fim de trazer maior riqueza para o presente trabalho e entendimento sobre os fenômenos ocorridos foram analisados documentos disponíveis nos canais de comunicação interna da organização. Dessa maneira, também a classificando como documental. Tais conteúdos demonstram os esforços corporativos com vistas à execução de ações em um contexto de mudança organizacional.

\section{MUDANÇAS NO MERCADO DE CONTEÚDO AUDIOVISUAL}

Em um estudo realizado por Rocha (2016) com o objetivo de entender o impacto das mudanças tecnológicas, novos modelos de geração, consumo e compartilhamento na distribuição de conteúdo audiovisual ficam evidente as mudanças pelo qual o segmento tem enfrentado ao longo do tempo. Com a evolução e inserção de novas tecnologias e 
iniciativas de sucesso à disposição dos consumidores de conteúdo audiovisual, o comportamento dos mesmos começou a modificar. O poder de escolha por meio do consumo de conteúdo sob demanda sempre esteve por trás dessa mudança. O conceito de consumo "anything, anytime, everywhere" ainda está presente nos dias de hoje e cresce cada vez mais.

A indústria da televisão, por sua vez, viveu um período de grande rentabilidade financeira em um modelo de alta produção de conteúdo não necessariamente desejado pelos telespectadores. Rocha (2016) acredita que o futuro da televisão está atrelado a uma mudança deste modelo, principalmente motivada pela crise global da indústria de publicidade ligada ao amadurecimento da internet. Uma vez que o seu sistema de distribuição de conteúdo é cada vez mais rápido, confiável, acessível e responsável por uma grande revolução global.

Em uma última e importante análise, a produção de bons conteúdos é trazida como foco das inovações que ocorrem atualmente no setor. As múltiplas plataformas disponíveis e acessíveis tornam o mesmo a atração principal aos consumidores. Por sua vez, o aumento dos conteúdos estimula cada vez mais a criatividade a fim de atrair novos telespectadores. As empresas inseridas no mercado de produção de conteúdo audiovisual precisam estar atentas à capacidade de resposta frente aos desafios impostos pelo mercado. É sob esse contexto que se faz necessário entender o conceito de Competências e Cultura Organizacional, tópicos os quais serão abordados no tópico seguinte.

\section{COMPETÊNCIAS E GESTÃO POR COMPETÊNCIAS}

Existem muitas definições sobre o conceito de competências. Tendo em vista que é um termo abrangente e muitas vezes dependem das crenças, cultura ou visão de cada um. Na análise de Parry (1996) a competência é vista como um arcabouço de conhecimentos, habilidades e atitudes relacionadas que constituem as responsabilidades e performance do profissional. Bem como, tais atributos podem ser medidos aprendidos. Pode-se dizer que existe forte correlação entre o aprendizado do indivíduo e o uso efetivo desses conhecimentos na sua realidade empresarial. Treinamentos poderão dar subsídios para aquisição de novas competências, entretanto, o aprendizado só poderá ser visualizado na prática através de um desempenho superior e/ou novas responsabilidades.

O conceito de Zarifian (2001, p. 68) é que "a competência é a inteligência prática para situações que se apoiam sobre os conhecimentos adquiridos e os transformam com tanto mais força, quanto mais aumenta a complexidade das situações". Essa visão denota que competência é não só uma consequência do conhecimento, mas também ações e aprendizados que se desenvolvem em experiências práticas e tomadas de decisões ao longo do tempo. Em outra análise, pode-se dizer que competência é ter know-how e atitude. Qualquer profissional obrigatoriamente estará no seu dia-a-dia interagindo com outras culturas, conhecimentos, opiniões, imprevistos e principalmente limitações das mais diversas espécies. Dessa maneira, pode-se dizer que um profissional é competente no sentido amplo e completo quando sabe mobilizar esforços nos mais diferentes contextos e superar as adversidades e entregar resultados.

A gestão de competências surge como uma maneira de gestão moderna que visa fomentar o desenvolvimento contínuo. Existe harmonia entre os desejos da organização e o autodesenvolvimento dos indivíduos. O modelo de gestão por competências ocorre a 
partir de mudanças profundas no tocante à formação de consciência crítica, possibilidade de trabalho com autonomia e interação com vistas à construção de novas competências. Esse modelo precisa funcionar em consonância a métodos justos e eficientes no que diz respeito à valorização, dessa maneira surge o modelo meritocrático que será abordado no próximo item.

\section{CULTURA ORGANIZACIONAL E MUDANÇA ORGANIZACIONAL}

Um clássico conceito formulado por Schein (1986) define cultura organizacional como um repertório de um grupo fruto do aprendizado coletivo na resolução de problemas, adaptação e integração. Nesse sentido, cada organização possui uma cultura distinta já que é um aspecto intrínseco a sua história. Em uma visão mais recente, Schein (2009) considera existirem suposições básicas assumidas pelos grupos e define a existência de níveis na cultura organizacional, quais sejam: artefatos; crenças e valores e suposições fundamentais básicas. O primeiro caracteriza-se pelos aspectos vistos, ouvidos ou sentidos quando uma pessoa entra em um grupo que não é o seu habitat familiar. Já as crenças e valores são o nível intermediário que abrange a interpretação trazida pelos colaboradores da organização já que é resultado da experiência social compartilhada que pode ou não ser validada e aceita por todos. Por sua vez, as suposições fundamentais básicas correspondem ao nível mais complexo que se refere à aspectos e fatos que não são amplamente discutidos organizacionalmente e, ao longo do tempo, já foram assumidos como verdadeiros em um consenso de indivíduos.

Uma gestão de pessoas moderna e estratégica não pode mudar a história que envolve a formação de determinada cultura organizacional. Porém, provavelmente terá como premissa fomentar a mudança cultural, sempre que necessária. Dessa maneira, viabilizar a formação de uma cultura adaptativa, inclusiva, flexível e com valores compartilhados entre todos os membros da empresa com vistas à inovação.

Acredita-se que o fracasso em processos de mudança organizacional muitas vezes se deve ao não planejamento e execução adequados de ações que necessitam do amplo engajamento dos colaboradores. Borges e Marques (2011) concordam e destacam que a situação gerada por um processo de mudança possui características não seguras e/ou tranquilas atreladas à complexidade de implementação e motivadas principalmente pela dificuldade de aceitação da mudança pelas pessoas envolvidas. Nesse contexto, a complexidade aumenta quando as organizações se submetem a processos de mudança estratégica uma vez que os programas interferem de forma substancial na cultura organizacional, códigos de comportamento, políticas e procedimentos de gestão, estrutura, poder e grupos de trabalho.

A implementação de uma Gestão Estratégica de Pessoas exige um processo de mudança organizacional profundo na organização devido a sua complexidade. Sua implementação é vital na sustentabilidade da organização já que reúne todas as ferramentas necessárias à manutenção de um ambiente sadio e produtivo englobando os conceitos teóricos descritos anteriormente. 


\section{GESTÃO ESTRATÉGICA DE PESSOAS}

Atualmente a tecnologia, conhecimento e globalização afetam diretamente a forma pela qual as empresas fazem gestão e podem conquistar o seu diferencial competitivo. É nesse contexto que Silva $(2005$, p. 26) afirma "uma organização que aprende é uma organização capacitada em criar, adquirir e transferir conhecimentos, modificando seu comportamento de forma a refletir nossos conhecimentos e insights". As mudanças estão ocorrendo diariamente e cabe às organizações que pretendem crescer nesse cenário estarem atentas às necessidades que o mercado impõe e responder de forma rápida e criativa.

Em paralelo ao aprendizado contínuo, multiespecialização e autonomia no trabalho emerge a necessidade cada vez maior de produtividade satisfatória a fim de atender as demandas, bem como, indicadores eficientes para mensurar e apontar a direção adequada para os executivos das organizações. É fundamental entender que mesmo no contexto de alto rendimento esperado dos profissionais o foco é nas próprias pessoas e no seu desenvolvimento.

A Gestão Estratégica de Pessoas é entendida como a união de todas as ferramentas necessárias e aplicáveis na realidade da empresa com o objetivo de alavancar os resultados do negócio. Isso se dá através da visão compartilhada e equilíbrio na satisfação e desempenho de todos os recursos humanos que compõe a organização na mesma velocidade em que são executadas quaisquer mudanças necessárias. Nesse sentido, meritocracia, gestão da diversidade e liderança participativa foram alguns aspectos que receberam destaque na abordagem da pesquisa qualitativa.

\section{ESTUDO DE CASO}

Em consonância aos objetivos do presente trabalho foram entrevistados líderes da organização a fim de identificar a percepção dos mesmos no tocante à mudança de cultura organizacional e evolução das estratégias de recursos humanos. Dessa maneira, pôde-se avaliar como as estratégias e processos de recursos humanos teóricos explicitados ocorrem na prática da gestão de equipes. Tendo em vista que o objetivo é posto a fim de perceber a evolução e influência ao longo do tempo os próximos itens são divididos em passado, presente e futuro a fim de possibilitar a convergência das percepções dos colaboradores com a análise crítica do autor de acordo com cada época analisada na empresa.

Buscou-se identificar as visões de passado, presente e futuro por meio de entrevistas com 5 colaboradores que atuam em cargos de gestão de uma diretoria específica da organização. Para que os entrevistados pudessem ficar à vontade para responder perguntas no tocante a decisões estratégicas de sua gestão e abordar visões críticas sobre o RH da organização suas identidades não serão expostas no presente trabalho. Foram entrevistados líderes com os seguintes perfis: colaborador que está na organização há 23 anos (Diretor); há 16 anos (Gerente); há 13 anos (Gerente); há 12 anos (Gerente) e um colaborador que está na organização há 1 ano (Gerente). Uma vez que o processo de amostragem foi por acessibilidade teve-se a premissa de entrevistar colaboradores que atuam na área de Recursos Humanos com o objetivo de identificar mais detalhadamente percepções e estratégias desse mesmo setor. Os entrevistados 
foram: colaborador que está na organização há 5 anos (Gerente $\mathrm{RH}$ ) e um que está há 4 anos (Parceiro de RH).

\subsection{Visão de Passado}

No que diz respeito à visão de passado é pertinente trazer a visão de um dos entrevistados ao reforçar o fato de que as ações de Recursos Humanos historicamente eram vistas como aparentemente ligadas à um interesse genuíno por pessoas, pouco executáveis ou planejáveis. Acredita-se que quaisquer análises nesse sentido devam ser contempladas justamente sobre a ótica de que a Gestão Estratégica de Pessoas é um conceito moderno atrelado à uma significativa evolução das organizações em consonância à Tecnologia, principalmente em uma empresa de criação, produção e distribuição de conteúdo audiovisual onde o presente estudo de caso é executado.

A visão que os entrevistados têm em relação ao passado da organização demonstrou estar bastante ligada a um perfil familiar e patriarcal que a empresa tinha em um contexto de produção audiovisual menos formal no que tange a uniformidade de processos, estrutura e comportamentos organizacionais. Nesse sentido, a maioria dos líderes afirmou perceber as ações de Recursos Humanos na organização como não estruturadas. O que fica evidenciado em um depoimento: "Há 30 anos atrás o nível dos profissionais contratados não era de nível universitário. Essas pessoas entravam aqui com um cargo operacional e ao longo do tempo iam crescendo até se tornarem Diretores" e descrever o fato de que muitas vezes esses profissionais não tinham o perfil ou competências ideias para atuação em determinada função e afirmar que na mesma época ficou surpreso ao entrar na organização e se deparar com um contexto pouco corporativo e desorganizado.

De modo geral a cultura organizacional no passado é vista pelos gestores como bastante atrelada ao relacionamento mútuo, sentimentalismo de todos colaboradores pelo core business da organização e paternalismo por parte das lideranças. Isso evidencia novamente que nos níveis mais superficiais da cultura provavelmente ainda não existiam instrumentos formais que suportam a gestão.

A análise de um dos entrevistados caracteriza a história da organização como altamente hierarquizada com consequências comportamentais perceptíveis nos colaboradores tal como o medo. Essa visão é interessante uma vez que traz uma reflexão acerca de como os relacionamentos se davam. Apesar da empresa ser essencialmente criativa acredita-se que não havia um ambiente favorável à inovação, caracterizado por um direcionamento consistente, autonomia dos profissionais e maestria dos gestores para lidar com os erros. A suposição é de que o talento criativo e artístico, aliado às demais características da cultura organizacional, eram vistos apenas como competências individuais.

Aspectos da cultura organizacional trazidas por gestores entrevistados com maior tempo de casa são valiosas uma vez que dizem respeito entendimento dos colaboradores a respeito de orçamento, produtividade e sustentabilidade de produções. Os depoimentos são de que não havia a corresponsabilidade e amplo entendimento de toda equipe a respeito da importância de produzir conteúdo que fossem não só valiosos artisticamente como competitivos no que diz respeito à melhor utilização de todos recursos envolvidos. 
Um dos líderes entrevistados trouxe uma análise que diz respeito a mudanças organizacionais ocorridas anteriormente. Segundo ele, as comunicações não foram tão bem-sucedidas. É provável que a empresa ainda não tivesse atuando em práticas e ferramentas que possibilitam uma comunicação mais clara e transparente aos colaboradores sobre a visão da organização em consonância às decisões tomadas pelos gestores.

É nesse âmbito que se torna importante a análise dos profissionais entrevistados de Recursos Humanos uma vez que diz respeito ao perfil dos gestores que faziam parte da organização. A percepção é de que os mesmos eram extremamente técnicos e operacionais, na maioria das vezes estavam desconectados do mercado e com nível básico em competências de liderança. Acredita-se que a organização ainda não tenha recrutado ou desenvolvido os profissionais que seriam os grandes propulsores da mudança estratégica e cultural que viria alguns anos depois. Isso não é visto como um problema já que a organização nunca precisou que seus profissionais possuíssem um pensamento e atuação estratégica já que a visão de passado estava atrelada ao share de mercado consagrado que a organização detinha na televisão aberta. De fato, a organização era reconhecida como uma empresa de vínculo empregatício estável.

Em um contexto de mudança cultural organizacional em vias da implementação de uma gestão estratégica é importante analisar que existe uma grande quebra de paradigmas entre a visão de passado para a visão de presente. Conforme apresentado anteriormente, a empresa se detinha à produção para a televisão aberta. Sendo assim todos os entrevistados participantes ressaltaram uma complexa modificação atrelada à evolução tecnológica e concorrência da organização com diversos novos players na disponibilização de conteúdo em diversas plataformas.

\subsection{Visão de Presente}

O cuidado com pessoas é uma característica percebida como muito forte na visão de presente dos entrevistados. Sendo um dos norteadores estratégicos a priorização dos talentos humanos, o depoimento das lideranças é de que existe a realização efetiva e explícita de ações estruturadas no que tange uma gestão de recursos humanos cada vez mais efetiva na organização. Nesse âmbito, acredita-se que já existe uma ruptura significativa em relação à visão de passado.

A percepção quanto à mudança estratégica é de que Diretoria está não somente definindo e comunicando os conceitos como também atuando de forma estratégica. Os grupos de trabalhos formados com equipes multidisciplinares para revisões de processos importantes são trazidos como um exemplo de uma mudança no que tange colocar as pessoas no centro das decisões. No entanto, a percepção de alguns líderes entrevistados é de que ações nesse sentido ocorrem área estudada, mas ainda não são realidade no âmbito da organização como um todo já que ainda existe muita hierarquia percebida nos processos internos.

Ao serem questionados sobre a aplicabilidade dos imperativos estratégicos na organização os entrevistados da área de Recursos Humanos ressaltam a importância do papel das lideranças e afirmam que a organização já possui profissionais capacitados para a execução das ações esperadas. Inclusive analisam positivamente que os gestores não aderentes já são naturalmente influenciados pelos primeiros. No entanto pontuam que a 
empresa ainda apresenta um nível básico no que diz respeito a aplicabilidade de ferramentas, muitas vezes básicas, de recursos humanos. Isso é exemplificado ao ressaltar que a área ainda precisa reforçar continuamente a importância de realização do feedback enquanto outras corporações no mercado já estão modificando totalmente o conceito e aplicabilidade do mesmo.

O tamanho e variedade de perfis que fazem parte da organização é trazido pelos profissionais de Recursos Humanos como uma complexidade no sentido de alcançar um olhar estratégico único. Nesse ponto a visão de um dos entrevistados é de que existem diferenças perceptíveis de uma área para a outra no alcance do olhar estratégico.

Quanto à visão geral de presente se torna valioso analisar a percepção de um dos entrevistados ao mencionar que se sente muito satisfeito com a confiança, autonomia e expectativa positiva que a empresa e seu gestor direto depositam no seu trabalho, principalmente no que tange à gestão de pessoas. Nessa linha, o entrevistado afirma que gosta de trabalhar junto ao seu "time" dando liberdade para que exista espaço para criatividade, ações intuitivas, implementação de novas ideias e aprendizado com erros. Essa visão é muito interessante pois a atmosfera retratada é de um ambiente fértil para a inovação e aderente aos conceitos de uma liderança participativa.

Um dos gestores entrevistados atribui grande valor à troca de conhecimentos de funcionários antigos com o grande número de novos talentos contratados recentemente na área em vistas da construção da nova cultura. Não é sabido se existe uma estratégia corporativa no que diz respeito à gestão da diversidade, porém no depoimento do entrevistado foi percebida uma atuação que converge para o exercício desse conceito. Em contrapartida nas entrevistas com a área de Recursos Humanos foi apontado que existe uma estratégia no que tange a renovação das lideranças, inclusive com uma taxa estimada superior a $50 \%$ nos últimos cinco anos, considerada fundamental em um contexto de mudança organizacional.

Um dos líderes afirmou: "hoje em dia já existe um grande orgulho das equipes por estarem construindo um produto de sucesso e não mais apenas pela história que está sendo contada" quando fez referência ao êxito de uma produção audiovisual que está sendo reconhecida pela execução conforme as diretrizes propostas pela organização em consonância ao sucesso percebido por telespectadores, clientes internos e externos. Ele identifica modificações na cultura organizacional, principalmente no tocante a adoção e construção conjunta de normas, políticas e processos, disponíveis a todos na organização.

É pertinente valorizar a importância atribuída ao Código de Ética e Conduta e a mitigação de diversos desvios que na visão de passado ocorria sem uma ferramenta formal que pudesse apoiar à gestão. Segundo a visão de presente do gestor entrevistado, as pessoas já apresentam um comportamento substancialmente diferenciado, tal qual o desejado no código da organização.

Dois entrevistados ressaltaram aspectos extremamente positivos na cultura organizacional que se referem à identificação e alinhamento de propósitos percebidos entre os colaboradores e a organização. Acreditam que o nicho de negócio criativo e de entretenimento possibilita uma proximidade e engajamento não só entre colaboradores como também com as pessoas que fazem parte dos seus cotidianos. Além disso, existe um orgulho, camaradagem e senso de pertencimento existentes nos diversos grupos. É uma preocupação manter tais aspectos vivos na empresa independente de quaisquer mudanças executadas. 
Conforme salientado pelas lideranças entrevistadas existe uma lenta velocidade percebida em como a mudança ocorre no âmbito da cultura organizacional, provavelmente nos níveis mais profundos como a teoria evidencia. A visão dos entrevistados da área de Recursos Humanos é de que o processo é realmente lento principalmente pelo tamanho da organização e a quantidade de aspectos a serem tratados. Conforme um dos gestores aponta, a mudança cultural na organização está fortemente ligada à forma pela qual as pessoas se relacionam com a tecnologia. É nesse âmbito que já existe forte contraponto à visão de passado uma vez que atualmente as pessoas são vistas como prioridade, o que traz consigo a responsabilização e empowerment dos mesmos no que diz respeito ao seu desenvolvimento e carreira.

Um dos gestores entrevistados ao relatar sua atuação em projetos que a organização fez em parceria com empresas do mercado, outro aspecto muito importante do novo posicionamento estratégico, afirmou que precisou ter uma visão de cliente muito mais aguçada e pôde trabalhar com uma dinamicidade diferenciada tal qual o mercado atua. Nesse sentido outro gestor traz o entendimento de que a organização já é capaz e se dispõe aos desafios de executar entregas customizadas à pluralidade das novas necessidades de consumo do conteúdo audiovisual, porém ainda é um desafio superar burocracias internas e modificar o mindset de muitos colaboradores que valorizam às produções de conteúdos mais tradicionais, executados com uma complexidade muito maior e já consolidados na televisão aberta, em detrimento às outras do seu portfólio.

Corroborando com as afirmações desse gestor, outro entrevistado assevera que as equipes muitas vezes esperam que os clientes e parceiros se adequem às regras internas ao invés de perceber que o desejado pela organização é o inverso. De modo geral, os gestores relatam que existe a priorização da produção de conteúdos diferenciados e com qualidade e o fomento a parcerias, tal qual a estratégia empresarial norteia, no entanto é também esperado pela organização uma atuação mais austera no que diz respeito à custos, equipes flexíveis e mais eficientes.

Os profissionais de Recursos Humanos reforçam como fundamental o papel das lideranças ao afirmar não ser possível modificar a cultura sem o patrocínio, exemplo e desdobramento das melhores práticas pelos gestores uma vez que a mudança cultural ocorre de cima para baixo, conforme a teoria estudada propõe. Nesse contexto existe um desafio na organização no que diz respeito ao amplo entendimento estratégico de tudo que está acontecendo por parte dos gestores, já que eventualmente os profissionais que possuem um mindset mais criativo apresentam certa dificuldade para entender aspectos mais corporativos da mudança.

Quanto ao desenvolvimento de colaboradores e lideranças em consonância à estratégia organizacional, a opinião dos gestores é que existe significativo esforço em execução. Isso é evidenciado ao possibilitar o desenvolvimento formal dos colaboradores através da disponibilização de conteúdos modernos na Universidade Corporativa que foi implantada há cerca de quatro anos, e agora conta com uma escola online específica atrelada à Tecnologia. Os entrevistados da área de Recursos Humanos evidenciaram a relevância que a Universidade possui e afirmam que existem conteúdos de altíssima qualidade à disposição dos colaboradores.

Vale destacar a percepção de uma das lideranças que aponta a forte correlação de cases do mercado sendo explorados nos treinamentos da organização e o fomento à aplicabilidade e aderência das teorias em práticas modernas de criação, produção e 
distribuição do conteúdo audiovisual na organização. No entanto, esse mesmo gestor tem dúvidas se as equipes se sentem motivadas, responsáveis pelo próprio desenvolvimento e conectam os conteúdos disponibilizados pela Universidade Corporativa com os imperativos estratégicos. Segundo ele, a motivação para o autodesenvolvimento é muito mais evidente junto às lideranças. Essa opinião é corroborada no depoimento de outro entrevistado.

Outra liderança entrevistada destacou a importância de ações não formais de desenvolvimento quando fala sobre uma comunicação aberta e fluida junto à sua equipe e afirma que o aprendizado é consequência de erros, acertos e questionamentos. Esse entrevistado informou que faz rodas de conversas semanalmente no projeto que atua e não acredita que sem esse diálogo conseguiriam alcançar os objetivos. Nesse sentido, aspectos de uma atuação como liderança participativa que possibilita feedbacks contínuos são evidenciados nesse discurso. Ainda nesse âmbito, o entrevistado trouxe a valiosa percepção no que diz respeito à sua equipe sobre estarem mais voltados para rotina operacional e especificidades do projeto que atuam em detrimento à uma visão compartilhada. Por isso entende como fundamental o seu papel em fomentar uma análise crítica no que diz respeito a diversidade de formatos de produção existentes dentro e fora da organização.

Quando se fala no desenvolvimento de lideranças um dos entrevistados ressaltou que os diálogos com seus superiores têm sido cada vez mais agregadores já que têm trazido clareza e direcionamento. Percebe que seu desenvolvimento tem sido grande devido à confiança e autonomia que os mesmos depositam em seu trabalho. Por sua vez, a área de Recursos Humanos afirma que através do seu modelo de atuação formado por HRBPs (Human Resources Business Partners) tem contribuição direta no desenvolvimento e suporte de gestores já que os profissionais são focados no atendimento de cargos de liderança.

A percepção quanto às novas contratações de lideranças é bastante positiva uma vez que os profissionais que acabam de chegar na organização já dominam importantes ferramentas de gestão. A análise de um dos líderes entrevistados é de que existe uma preocupação da organização em trazer do mercado um arcabouço de competências de gestão que ao serem aplicadas agreguem valor ao profundo conhecimento do negócio que já faz parte do capital intelectual da organização. A percepção é corroborada nas entrevistas com os profissionais de Recursos Humanos que adicionam a visão de que diversos novos líderes estão apresentando alto desempenho, bem como servindo de modelo aos demais.

O plano de carreiras por meritocracia, implantado recentemente na área em que os entrevistados estão inseridos, é visto como bastante benéfico. Os argumentos são dados com base em um aspecto mais prático e objetivo que é o aumento na remuneração da equipe, com impacto motivacional principalmente em cargos juniores, como também no fato de a organização chancelar o conceito de mérito em si. Uma vez que o modelo propõe a valorização rápida e formal dos profissionais que estejam dispostos a assumir novos desafios de liderança. Além disso, são percebidos aspectos inerentes que giram em torno da valorização da carreira em si e auxiliam as lideranças em uma gestão de desempenho ainda mais formal e eficaz.

Quanto ao conceito de meritocracia em si, é argumentado que o mesmo ainda não pode ser aplicado em sua plenitude já que existe um grande passivo advindo de um 
histórico em que o desenvolvimento das carreiras no sentido das movimentações, promoções e mérito não eram necessariamente atrelados à performance dos profissionais. A percepção é de que ainda existe um aprendizado nas lideranças em lidar de uma forma menos emocional com a gestão do desempenho. Além disso, se faz necessária uma comunicação mais transparente, fluida e consistente a respeito das metas de desempenho estabelecidas no sentido de deixá-las menos subjetivas e capazes de serem aferidas com maior consistência.

Quanto à produtividade o entendimento da maioria dos gestores é de que a mesma não modificou, em contraponto ao aumento na qualidade das conforme o posicionamento estratégico da empresa preza. Na visão de presente existem uma série de normas que tornam o trabalho da carreira em questão cada vez mais complexa uma vez que existe um arcabouçou de responsabilidades no que tange ao cumprimento à legislação, atuação junto à comunidade e governantes, respeito à funcionários e fornecedores. Bem como, uma ousadia esperada e crescente motivada pela criação e produção de conteúdos cada vez mais atraentes. A visão é de que a priorização da empresa pela qualidade, atrelada à novas exigências acima descritas, trouxe a necessidade de os profissionais dessa carreira acompanharem números com maior afinco e necessidade de buscarem cada vez mais soluções criativas tendo como objetivo final uma maior competitividade do produto final no mercado nacional e internacional.

Outra liderança ao analisar o conceito de produtividade da empresa como um todo acredita que ainda não exista uma comunicação fluida e negociação totalmente satisfatória entre cargos que conceitualmente já tem poder de decisão igualitário no mercado mundial, uma vez que possuem competências extremamente estratégicas no processo produtivo. Segundo ele existem profissionais de outras carreiras que ainda assimilam certos posicionamentos e a sinalização de recursos limitados de uma forma pessoal e emocional. No entanto, percebe que já existe mudança substancial nesse âmbito principalmente nas interações que teve com novos profissionais de mindsets diferenciados ocupando essas posições.

Na visão de Recursos Humanos todos esforços realizados nos últimos anos com vistas a uma mudança cultural e estratégica tem impacto diretamente na produtividade. Espera-se que a organização tenha cada vez mais uma gestão de performance eficaz, prérequisito para que os melhores talentos façam parte da corporação. Já houveram diversos ganhos nesse sentido, mas ainda existem muitas oportunidades principalmente no que diz respeito à separação do que é camaradagem para o que efetivamente foi a entrega dos profissionais. Existe uma grande sensibilização no que diz respeito a esse papel ser do gestor e a área de $\mathrm{RH}$, através do seu modelo de atendimento, estar muito próxima a ele para suportar todo processo.

De acordo com os depoimentos dos entrevistados o clima organizacional é visto como melhor do que no passado, mas não totalmente satisfatório. Nesse âmbito um dos líderes entrevistados acredita que clima poderia ser melhor porque muitas vezes percebe sua equipe e até mesmo outras lideranças confusas com decisões e mudanças organizacionais estratégicas. Segundo ele, existe uma comunicação aberta e feedbacks recorrentes puxados por si mesmo junto aos seus liderados, no entanto os mesmos também esperam um diálogo mais aberto e fluido com os líderes de hierarquia mais alta. Corroborando com essa visão outro líder acredita que o clima organizacional é significativamente diferenciado em projetos que atua com o apoio de uma comunicação 
mais fluida junto às equipes vinda de profissionais que ocupam cargo de direção. Além disso, afirma que produções sustentáveis e de sucesso tendem a apresentar um clima organizacional superior às demais.

De modo geral o depoimento da maioria dos entrevistados sinalizou as significativas e recorrentes mudanças pelas quais a organização passa como entraves na evolução dos índices de favorabilidade quanto ao clima organizacional. Os profissionais de Recursos Humanos entrevistados corroboram com essa visão ao trazerem argumentos conceituais a respeito da mudança conforme os estudados. Os quais dizem respeito à complexidade de se manter uma percepção de clima satisfatória e engajamento uma vez que mudanças geram incertezas humanas. É um desafio obter ganhos nesse sentido principalmente em uma empresa que ainda possui relações extremamente pessoais e afetivas entre os colaboradores.

Em suma a percepção das lideranças quanto ao presente está atrelada a uma valorização da Gestão Estratégica de Pessoas uma vez que são esperadas competências diferenciadas dos profissionais em um contexto de constante mudança no formato pelo qual todo o mundo se relaciona com a tecnologia. Por sua vez, a área de Recursos Humanos já é vista como mais presente e atuando de forma estratégica ao lado dos gestores entrevistados, inclusive com profundo conhecimento do negócio.

\subsection{Visão de Futuro}

Existe uma grande energia a fim de fomentar a agilidade, atitudes práticas e decisões objetivas que modifiquem a forma pela qual as relações e processos ocorrem. Trabalhar com a diversidade, empatia e resiliência são algumas competências esperadas nas equipes que são destacadas nos discursos de algumas lideranças entrevistadas. Nesse sentido, a visão é de que o mundo moderno irá cada vez mais necessitar que os profissionais possuam competências para se manterem competitivos e cabe à Gestão Estratégica de Pessoas suportar esses profissionais.

A visão de um dos entrevistados denota: "as organizações precisam estar preparadas para absorver esses profissionais e assegurar que os mesmos tenham uma contribuição significativa. Saímos de um lugar em que RH é focado em atração, recrutamento, seleção, desenvolvimento e assume um lugar de gestão de talentos" ao se referir sobre a importância da área de Recursos Humanos em um contexto onde cada vez mais tarefas podem ser robotizáveis.

Na visão dos gestores entrevistados o cenário futuro em uma empresa de criação, produção e distribuição de conteúdo audiovisual está mais do que nunca atrelado à gestão de talentos humanos capazes de agregar valor em um contexto de inteligência artificial. A percepção é de que existe um complexo desafio com vistas à sustentabilidade da organização através de produtos criativos e de qualidade que agreguem valor aos clientes.

Acredita-se que ainda existe um longo e desafiador caminho pela frente no que tange a mudança estratégica e cultural da organização estudada. Nos discursos dos profissionais da área de Recursos Humanos a teoria é confirmada já que os mesmos percebem como natural o tempo necessário para execução de mudanças tão profundas em uma organização grande e complexa como tal. Além disso, adicionam a percepção de que a empresa seja de fato muito cuidadosa na forma pela qual conduz essas mudanças. 
Quanto à meritocracia, conceito que é a espinha dorsal do plano de carreiras implantado recentemente, um dos gestores entrevistados ressaltou acreditar que a mesma seja possível de ser realizada em sua plenitude apenas daqui dois ou três anos.

Nesse sentido, percebe-se que a empresa ainda poderá ter muitos ganhos no que tange uma gestão de desempenho cada vez mais eficaz atrelada às competências que são necessárias à sua sustentabilidade. A visão de futuro é de que as mudanças sejam ainda mais alavancadas ao longo desse e dos próximos anos uma vez que existem projetos corporativos em execução que visam uniformidade e inovações extremamente estratégicas. Acredita-se ser muito importante uma comunicação cada vez mais clara e eficaz que seja capaz de atingir todos públicos.

\section{CONSIDERAÇÕES FINAIS}

Quando é analisada a evolução das estratégias de recursos humanos vale perceber que a origem da organização é familiar, paternalista, hierarquizada e com relações corporativas não estruturadas. Isso é evidenciado no que diz respeito a não existência de políticas, processos e ferramentas formais que possam ser consideradas parte de uma gestão estratégica de pessoas. A análise é de que a empresa não exigia de seus colaboradores um pensamento estratégico uma vez que detinha um posicionamento e receitas satisfatórias no mercado de criação, produção e distribuição de conteúdo audiovisual.

De modo geral pode-se dizer que a visão de passado é de que os colaboradores nutriam grande sentimentalismo entre si e ao core business em um contexto de apogeu organizacional onde possivelmente as competências individuais dos colaboradores eram supra valorizadas em detrimento às demais.

Ao longo do tempo com a evolução das tecnologias e principalmente com a expansão da internet percebe-se que a organização constatou a necessidade de mudanças através da adoção de uma estratégia organizacional que pudesse suportar a sustentabilidade de seus resultados. O presente trabalho possibilitou a análise de que a partir do momento em que essa a nova estratégia foi definida iniciaram-se uma sucessão de grandes mudanças culturais em consonância uma participação cada vez mais efetiva da área de Recursos Humanos nas tomadas de decisões.

A visão de presente acerca da cultura empresarial denota que já houveram significativas modificações no sentido de tornar a empresa cada vez mais organizada e corporativa. Nesse sentido, à luz da teoria conceituada por Schein é evidente que a organização evoluiu no que diz respeito à sua estrutura, processos, estratégias, metas e filosofias. No entanto para que existam modificações em aspectos mais profundos da cultura, denominados por esse mesmo autor como pressuposições básicas, acredita-se que ainda seja necessário um grande esforço a ser executado pelas lideranças. Principalmente através de uma comunicação mais clara, assertiva e direcionadora, a respeito das tomadas de decisões em consonância às exigências que uma empresa mediatech necessita para ser sustentável no mercado audiovisual.

Acredita-se que as dificuldades atreladas à mudança de cultura estejam vinculadas ao grande tamanho, diversidade de perfis, competências e subculturas organizacionais desenvolvidas ao longo do tempo de existência da corporação. Acredita-se que seja natural o entendimento e engajamento dos colaboradores em um pensamento e atuação 
estratégica levarem algum tempo até serem disseminados uma vez que por muito tempo a empresa não exigiu isso dos seus colaboradores. É nesse sentido que se percebe uma estratégia clara no que diz respeito ao desenvolvimento e contratação de lideranças preparadas para executar uma gestão eficaz no novo panorama projetado. Ao longo dos últimos anos a empresa de fato buscou se estruturar para que tivesse em seu time pessoas preparadas para serem guardiãs e catalizadoras do novo contexto empresarial desejado junto às equipes.

Quando se fala sobre uma gestão estratégica de pessoas se tornou pertinente analisar os conceitos de competência e meritocracia na forma pela qual a organização gere seus talentos. Pode-se dizer que já existe clareza sobre os ganhos práticos já que existe o desdobramento da estratégia em competências ou valores esperados nos colaboradores. No entanto acredita-se ainda ser embrionária a aplicabilidade da meritocracia na área estudada pois ainda existe um grande desafio advindo da visão de passado. O entendimento é de que os ganhos poderão ser vistos em sua plenitude em pouco tempo uma vez que todos entrevistados, responsáveis por uma gestão do desempenho cada vez mais estruturada, correlacionam os benefícios de um plano de carreira em uma performance superior esperada em seus times.

O aumento na favorabilidade quanto a clima organizacional é visto como bastante complexo na visão dos profissionais participantes no estudo de caso. Existe uma preocupação da organização em manter os níveis satisfatórios já que periodicamente a empresa afere e executa uma série de ações com vistas a promoção do engajamento, no entanto é perceptível a velocidade pela qual as mudanças têm ocorrido causam por si só certa desconfiança no comportamento das equipes. É nesse âmbito que novamente são evidenciadas as competências de liderança como fundamentais através de uma comunicação clara e direcionadora que possibilite a visão compartilhada acerca dos rumos almejados.

Em suma os relatos quanto à visão de futuro corroboram com a importância atrelada ao alinhamento de propósitos humanos, empatia nos relacionamentos, desenvolvimento de perfil e carreira. Uma vez que a robótica e inteligência artificial apoiarão na automatização dos processos extremamente operacionais, espera-se uma participação proativa e criativa dos profissionais na construção da sua carreira. Os quais sejam capazes de formar times de alta performance responsáveis por garantir a sustentabilidade da organização como mediatech presente na vida dos demais colaboradores, parceiros e clientes.

\section{REFERÊNCIAS BIBLIOGRÁFICAS}

BORGES, Renata Simões Guimarães E; MARQUES, Antônio Luiz. Gestão da Mudança: Uma Alternativa para a Avaliação do Impacto da Mudança Organizacional. Estudo publicado em Faces: Revista de Administração, 01 September 2011, Vol.10 (1). Disponível em: <http://www.fumec.br/revistas/facesp/article/view/528/517> Acesso em 12/03/2019.

BOWDITCH, James L; BUONO, Anthony F. Elementos de comportamento organizacional. São Paulo: Pioneira Thomson Learning, 2004. 
CHIAVENATO, Idalberto. Gestão de Pessoas: e o novo papel da gestão de pessoas. Rio de Janeiro: Elsevier, 2004. 7ạ. Reimpressão - Programa do Livro Texto (PLT).

DAVIS, Keith; NEWSTROM, John. W. Comportamento humano no trabalho: uma abordagem psicológica. São Paulo: Pioneira, 1992.

HANASHIRO, D. M. M. Gestão do fator humano: uma visão baseada em stakeholders. São Paulo: Saraiva, 2008.

KRUGER, Eduardo. Motivação: um novo modelo de gestão. Disponível em: $<$ http://revistavocerh.abril.com.br/materia/motivacao-um-novo-modelo-degestao>Acesso em: 10 Out. 2013.

LACOMBE, Francisco.; HEIBORN, Gilberto. Administração: princípios e tendências. São Paulo: Saraiva, 2 ed. 2008.

PALMEIRAS, Rafael. Meritocracia ganha espaço nas empresas brasileiras. Disponível em: <http://www.brasileconomico.ig.com.br/noticias/meritocracia-ganha-espaco-nasempresas-brasileiras 123947.html> Acesso em: 06 Out. 2013.

PARRY, S. B. The quest for competencies. Training, July 1996.

ROCHA, Edson Gomes da. Netflix o próximo passo da evolução televisiva. Dissertação de Mestrado, Pontifícia Universidade Católica de São Paulo, 2016, Disponível em:

< https://tede2.pucsp.br/handle/handle/19348>. Acesso em: 24/11/2018.

SCHEIN, Edgar H. Cultura Organizacional e Liderança; tradução Ailton Bomfim Brandão; revisão técnica Humberto Martiotti. São Paulo: Atlas. 2009.

SILVA, Mateus de Oliveira. Gestão de pessoas através do sistema de competências: estratégias, processos, desempenho e remuneração, fundamentos e aplicação. Rio de Janeiro: Qualitymark, 2005.

ZARIFIAN, Philippe. Objetivo competência: por uma nova lógica. São Paulo: Atlas, 2001.

WERTHER, W. B.; DAVIS, K. Administração de pessoal e recursos humanos. São Paulo: McGraw-Hill, 1983. 